\title{
O GERENCIAMENTO DA QUALIDADE POR MEIO DE FERRAMENTAS CORPORATIVAS
}

\author{
Eliane Garlet, Márcio José Ostapiuk²
}

\begin{abstract}
RESUMO: 0 presente artigo tem por objetivo identificar as práticas do gerenciamento da qualidade utilizadas por uma empresa multinacional e as ferramentas corporativas que a mesma desenvolveu para atender as expectativas dos seus consumidores. Deste modo, o presente artigo é caracterizado como um estudo de caso de caráter qualitativo, onde as coletas de dados ocorreram através de questionários não estruturados com o supervisor da área de qualidade da empresa. Devido as questões de confidencialidade, alguns dados pontuais não puderam ser aprofundados. Como principais resultados foram apresentadas ferramentas corporativas desenvolvidas pela empresa para resolver os problemas de não conformidades presentes em seus processos produtivos, como a quality-note que se divide em três tipos, e detalha como é realizada abertura da mesma. Outra ferramenta é Non-Conformance Corrective Action utilizada para resolução de problemas mais críticos dos processos e Corrective Action Report para problemas que não podem ser resolvidos dentro do prazo. Diante dos resultados pode-se perceber a importância do gerenciamento da qualidade para as grandes empresas, principalmente para a empresa estudada, que tem como foco principal a qualidade em tudo que produz, buscando ferramentas cada vez mais complexas e detalhadas para resolução de problemas de não conformidade, diminuindo os custos operacionais, pelo menor esforço, tanto em precisão como na redução de desperdícios. Ao final, todos os resultados enaltecem que os clientes são o foco principal das atividades desenvolvidas pela empresa, ou seja, atender as necessidades e especificações desejadas.
\end{abstract}

Palavras-chave: Gestão da qualidade. Gerenciamento da qualidade. Ferramentas corporativas.

Submissão: 06/07/2020

Aceite: $28 / 09 / 2020$

DOI: 10.47591/RAC.2674-9203.2021v3n1.art1-1-13

Este trabalho está licenciado com uma Licença Creative Commons Atribuição-NãoComercial 4.0 Internacional.

\footnotetext{
${ }^{1}$ Bacharel em Engenharia da Produção pela Faculdade Horizontina. Mestra em Engenharia da Produção pela Universidade Federal de Santa Maria. E-mail: garleteliane@fahor.com.br.

${ }^{2}$ Tecnólogo em Gestão da produção industrial pela Uninter. Especialista em Engenharia de Produção pela Ulbra. E-mail: marciosapeco@yahoo.com.br.
} 


\section{INTRODUÇÃO}

Diante do contexto atual de constantes mudanças apresentadas no mercado competitivo, as empresas se veem perante grandes desafios para garantir seu sucesso e permanecer inseridas no mercado. Para isso, muitas adotam uma visão estratégica para desenvolver competências e habilidades por meio de gestão nas mais diferentes áreas. Desta forma, a empresa agrega valor nos seus processos e automaticamente aos seus negócios.

Dentro do cenário empresarial com a intensificação da concorrência em nível mundial, gerada especialmente, pela globalização das economias, a arte de gerenciamento da qualidade nos processos de manufatura passou a ser valorizada pelas organizações, além disso, a intensificação da concorrência no ambiente competitivo, demanda das organizações novas formas de gerenciamento para sobrevivência no mercado. Nesse sentido, as organizações precisam dispor de sistemas de produção e operação eficientes, para garantir vantagens competitivas frente aos concorrentes. Assim, o sucesso ou fracasso de uma empresa está ligado diretamente às estratégias competitivas, novas tecnologias de produção e a forma de gerenciamento da produção (COSTA et al., 2007; VOSS, 1995).

De acordo com Slack (2008), o gerenciamento da qualidade é visto atualmente como algo que pode ser universalmente aplicado em qualquer organização, sendo que o mesmo é de responsabilidade dos gerentes. 0 gerenciamento da qualidade tem por objetivo assegurar que todos os envolvidos tenham entendimento de sua importância, bem como saber aplicá-la na organização.

Como o desenvolvimento da era industrial é possível observar inúmeros benefícios vindos da qualidade nos processos produtivos, redução de custos, menos retrabalho, prazos de entrega, satisfação dos clientes, entre outros (VASCONCELOS et. al., 2009). A qualidade, cada vez mais, vem sendo relacionada com as necessidades dos clientes, o que eles procuram em um produto e o preço é um fator determinante decisivo no momento da compra (MARSHALL JUNIOR et al., 2008; HARTZ; OLIVEIRA, 2011).

Dentro do cenário atual de mercado e de competitividade, os clientes se tornam cada vez mais exigentes em termos de qualidade, fazendo com que as empresas estejam constantemente em busca de métodos ou ferramentas que possam atender essas exigências ou até mesmo se antecipar a elas. Uma empresa que busca se manter nesse mercado, intensifica suas pesquisas, busca entender e valorizar a opinião dos clientes, de modo a poder fidelizar o mesmo diante dos processos, produtos e serviços prestados, buscando atender as expectativas dos mesmos, por meio de uma gestão estruturada e com objetivos bem definidos.

Diante disso, o presente estudo teve como objetivo identificar as práticas do gerenciamento da qualidade utilizadas pela empresa, bem como as ferramentas corporativas, que a mesma desenvolveu para atender as expectativas dos clientes e permanecer como uma referência mundial em desenvolvimento de implementos no seu mercado de atuação. 


\section{REVISÃO DE LITERATURA}

\subsection{GESTÃO DA QUALIDADE}

O conceito de qualidade passou por uma evolução, da adequação aos padrões para às necessidades exigidas pelos clientes. Esta evolução da qualidade proporcionou as organizações um importante diferencial competitivo frente os seus concorrentes (SHIBA, GRAHAM, WALDEN, 1993; MARTINS, NETO, 1998).

Inicialmente, a qualidade estava restrita a um corpo de engenheiros e técnicos e, nos dias atuais, a qualidade além de ser essencial em qualquer organização, passou a ser uma responsabilidade de todos os colaboradores (FERREIRA, 2004; ALMEIDA, SOUZA, MELLO, 2010).

De acordo com Godoy et al. (2009), a qualidade é um requisito de mercado que necessita ser identificado e gerido de forma estratégica e operacional, constituindo um importante elemento competitivo. A qualidade de produtos e serviços não é definida pelas empresas, mas sim, pelos clientes (GAITHER, FRAZIER, 2002; ALMEIDA, SOUZA, MELLO, 2010).

Sob a ótica de Vasconcelos et al. (2012) e Araújo (2006), "as empresas estão lidando com clientes cada vez mais exigentes e conscientes das finalidades de consumo e da variedade de mercado com condições de lhes oferecer tais produtos". Perante esta realidade, considera-se que, a qualidade não está relacionada apenas a certificação do produto ou serviço, mas sim, pelo empenho das empresas em produzir com diferencial para que os clientes percebam isso.

0 conceito relacionado à gestão da qualidade varia constantemente e está vinculado a diversos fatores como necessidades dos clientes, custos, aparência, aplicabilidade, entre outros pontos que pode ser tratado sob muitas perspectivas (PLATH; KACHBA; DIAS; 2011). Para que os objetivos relacionados a gestão de qualidade sejam alcançados, as empresas precisam praticar a melhoria contínua, agindo em acordo com as especificações do cliente, que cada vez mais tem o poder de influenciar as diretrizes organizacionais, estimulando as empresas a buscarem o desenvolvimento de processos proporcionam qualidade, inovação e sustentabilidade (COTA; FREITAS, 2013).

As empresas tem se conscientizado da importância da gestão da qualidade, não apenas como produtividade, mas ligada a vários fatores de competitividade e a sua importância, na melhoria do aprimoramento dos produtos, processos e sistemas de gerenciamento. Percebe-se que, as organizações industriais que visam somente, a manutenção dos padrões de processos e produtos, não se tornam altamente competitivas. A competitividade está na melhoria contínua desses padrões, agregando valor aos produtos, mostrando que produz benefícios gerando mudanças positivas junto aos clientes e condições de competir com seus concorrentes.

\subsection{GERENCIAMENTO DA QUALIDADE}

As abordagens para o gerenciamento da qualidade têm sido de grande interesse para qualquer negócio que almeja a satisfação dos seus clientes. De acordo com Slack (2008), uma das mais importantes abordagens do gerenciamento da qualidade foi o Gerenciamento da Qualidade Total (GQT), que se tornou popular nas 
empresas nas décadas de 70 e 80, mesmo que estivesse baseada em trabalhos de outros pensadores do gerenciamento.

O GQT é um sistema permanente e de longo prazo voltado para a satisfação do cliente por meio da melhoria contínua dos produtos e serviços desenvolvidos pela empresa, contando com a participação de todos os membros da empresa, incluindo os colaboradores de chão de fábrica até a alta gerência, na busca do objetivo comum (MEARS, 1993 E LIMA; SANTIAGO, 2011). Para Coltro (1996) e Lima; Santiago (2011), as ações desenvolvidas pelo GQT devem ser através da consolidação de técnicas e ideias voltadas para o aumento da competitividade da empresa focando a melhoria dos processos e produtos.

$\mathrm{Na}$ Gestão da Qualidade no trabalho é de todos os envolvidos e tal pensamento deve contagiar todas as etapas do processo, dando origem a uma política organizacional que proporcione uma sinergia entre os departamentos e funcionários da empresa (LIMA; SANTIAGO, 2011). Desse modo, a gestão da qualidade vem a ser uma estratégia de competitividade e uma exigência essencial para uma organização (CARPINETTI, 2007).

\subsection{FERRAMENTAS E METODOLOGIAS DA QUALIDADE}

Ferramentas da qualidade são definidas como estratégias que melhoram a qualidade dos processos, melhorando os produtos e serviços. Tem como foco pesquisar, avaliar e propor melhorias e soluções para os problemas encontrados durante o processo que possam vir a interferir nos resultados (MIGUEL, 2006).

Segundo Freitas et al. (2014), as ferramentas da qualidade são empregadas para realizar estudos frente a problemas encontrados em um processo, desde sua definição até a proposição de soluções, passando pelos processos de medição e análise.

O PDCA também conhecido como ciclo de melhoria contínua, tem por objetivo identificar e organizar as atividades de um processo de solução de problemas de modo que venha a garantir, de maneira eficaz, o desenvolvimento de uma atividade planejada (LOBO, 2010).

As ferramentas da Qualidade são técnicas que muitas vezes são empregadas com o objetivo de definir, mensurar, analisar e propor soluções para problemas no meio fabril e que possam interferir no desempenho dos processos da organização. Foi na década de 50 que as ferramentas da qualidade foram desenvolvidas, a partir de práticas e conceitos existentes da época. A partir de então, elas têm proporcionando grandes vantagens aos sistemas de gestão, formando um conjunto de ferramentas estatísticas que possibilita a melhoria de produtos, serviços e processos (FREITAS et al., 2014).

\section{MÉTODO}

0 presente trabalho é caracterizado como um estudo de caso, de acordo com Gil (1999), uma vez que foram coletadas todas as informações necessárias em uma empresa de grande porte fabricante de implementos agrícolas, bem como fez análises indispensáveis conforme objetivo da pesquisa. Observa-se que este trabalho se definiu como estudo de caso, pois se trata de um caso único em uma 
empresa de grande porte localizada no sul do Brasil, em que são apresentadas a ferramentas corporativas utilizadas na busca pela melhoria da qualidade.

Destaca-se que quanto à natureza das variáveis pesquisadas, estas podem ser de ordem qualitativa ou quantitativa. Assim, com base no exposto, observa-se que o presente trabalho se caracteriza de acordo com Mattar (1999) como qualitativo, uma vez que o pesquisador realizou a coleta de dados referentes ao estudo em um ambiente real, tendo como foco principal o processo das atividades de gerenciamento da qualidade, de maneira qualitativa.

Para delinear as atividades que foram desenvolvidas, cada etapa do trabalho necessitou de um procedimento diferente para a estruturação das informações, devido ao estudo ter sido realizado em uma empresa de grande porte. 0 presente trabalho iniciou a realização da pesquisa através das coletas de dados, possibilitando ao pesquisador verificar informações pertinentes ao estudo, permitindo ao mesmo a previsão dos fatos (CHIZZOTTI, 1995).

A coleta de dados deu-se através de questionário não estruturado com supervisor da área de qualidade, possibilitando compreender todas as ações e ferramentas utilizadas. Através destas conversas, foi possível identificar quais as ações através dos exemplos de projetos aplicados na empresa, que por motivos de confidencialidade, os mesmos não puderam ser transcritos neste estudo. Deste modo, aqui foram relatadas as práticas que a empresa aplica na gestão da qualidade de seus produtos, bem como as principais ferramentas corporativas que a mesma desenvolveu diante das necessidades e perfis dos seus potenciais clientes.

\section{ANÁLISE E DISCUSSÃO DOS RESULTADOS}

Os dados coletados para o estudo, bem como os dados bibliográficos utilizados como referencial teórico, foram analisados perante os resultados obtidos na pesquisa. Primeiramente são explanadas as características da empresa onde foi realizado o estudo de caso e, posteriormente, a descrição dos dados estudados e sua interpretação.

\subsection{CARACTERIZAÇÃO DA EMPRESA}

Por motivos de confidencialidade o nome da empresa não pôde ser divulgado neste estudo. Todos as informações contidas neste estudo são apresentadas de forma pontual, mediante adaptações por exigência da empresa, sem comprometer a veracidade dos dados utilizados.

Conforme mencionado anteriormente, os dados referentes à empresa foram coletados através de questionamentos abertos com o supervisor da área de qualidade. Deste modo, trata-se de uma empresa multinacional, que ingressou no mercado brasileiro na década de 70 e, desde então, vem se destacando com seus produtos e tecnologias de ponta, empregados na melhoria continua e na busca constante da qualidade em seus produtos, serviços e processos.

A empresa conta com unidades instaladas pelo Brasil, e a unidade em que foi realizado o presente trabalho está localizada no sul do País, onde a mesma produz implementos agrícolas para o mercado nacional e internacional. A mesma possui um número aproximado de 1000 funcionários, com uma área coberta de mais 
de $68.000 \mathrm{~m}^{2}$, sendo uma das principais referências em termos mundiais em tecnologia em seu mercado de atuação.

\subsection{ATIVIDADES DE QUALIDADE ANALISADAS}

A empresa pesquisada tem a qualidade como um dos principais diferenciais em termos de produtos e processos. Diante disso, se faz um rigoroso gerenciamento de qualidade em todas as etapas dos processos, a fim de garantir maior satisfação e garantia de atender os requisitos requeridos pelo cliente.

Deste modo, ao surgirem problemas de qualidade nos processos, são utilizadas dentre outras metodologias e técnicas, três ferramentas corporativas para a resolução dos problemas detectados. Estas ferramentas utilizam como suporte as ferramentas de qualidade.

\subsubsection{Quality note}

A empresa pesquisada tem a qualidade como um dos principais diferenciais em termos de produtos e processos. Diante disso, se faz um rigoroso gerenciamento de qualidade em todas as etapas dos processos.

Uma Q-note é uma ferramenta que está vinculada ao sistema SAP® (Systems Applications and Products in Data Processing) utilizado pela mesma. Este possui transações que direcionam estas notas dependendo do tipo de não conformidade. A empresa trabalha com três tipos de Q-notes, destacadas como:

- Z1 - Q-notes de clientes mais utilizadas para devolução do concessionário de material não usado, não coberto pela garantia;

- Z2 - peças compradas onde o fornecedor está em falta;

- Z3 - defeitos causados pela empresa.

Ao serem detectados problemas em alguma área de processo, o colaborador solicita um inspetor da qualidade para análise do mesmo. Depois de verificada esta não conformidade são abertas notas denominadas Quality note (Q-note) no software de gerenciamento, de não conformidades que são disparados via e-mail, juntamente com um link direcionador as pessoas que serão responsáveis pela resolução deste problema.

A Q-note é uma ferramenta desenvolvida e utilizada pela empresa em todas as unidades em termos mundiais para registros de não conformidades. De maneira geral, uma notificação da qualidade pode ser utilizada para:

- Descrever problemas e identificar os objetos de referência afetados, como material, fornecedor e fabricante;

- Registrar os nomes das pessoas envolvidas no problema;

- Definir parâmetros de processamento para a notificação de qualidade;

- Registrar itens individuais com defeito relacionados ao problema e analisar suas causas;

- Especificar as ações corretivas a serem tomadas, por exemplo;

- Monitorar a execução das ações corretivas através de uma função de gerenciamento de status; 
- Registrar todas as atividades que foram realizadas para o problema e custos incorridos durante o processamento e correção de um problema;

- Permite gerar seletivamente listas de notificações registradas para fins de processamento ou avaliação.

A Figura 1 apresenta a imagem do sistema da empresa para abertura de uma Q-note.

Figura 1 - Abertura de uma Q-note via sistema

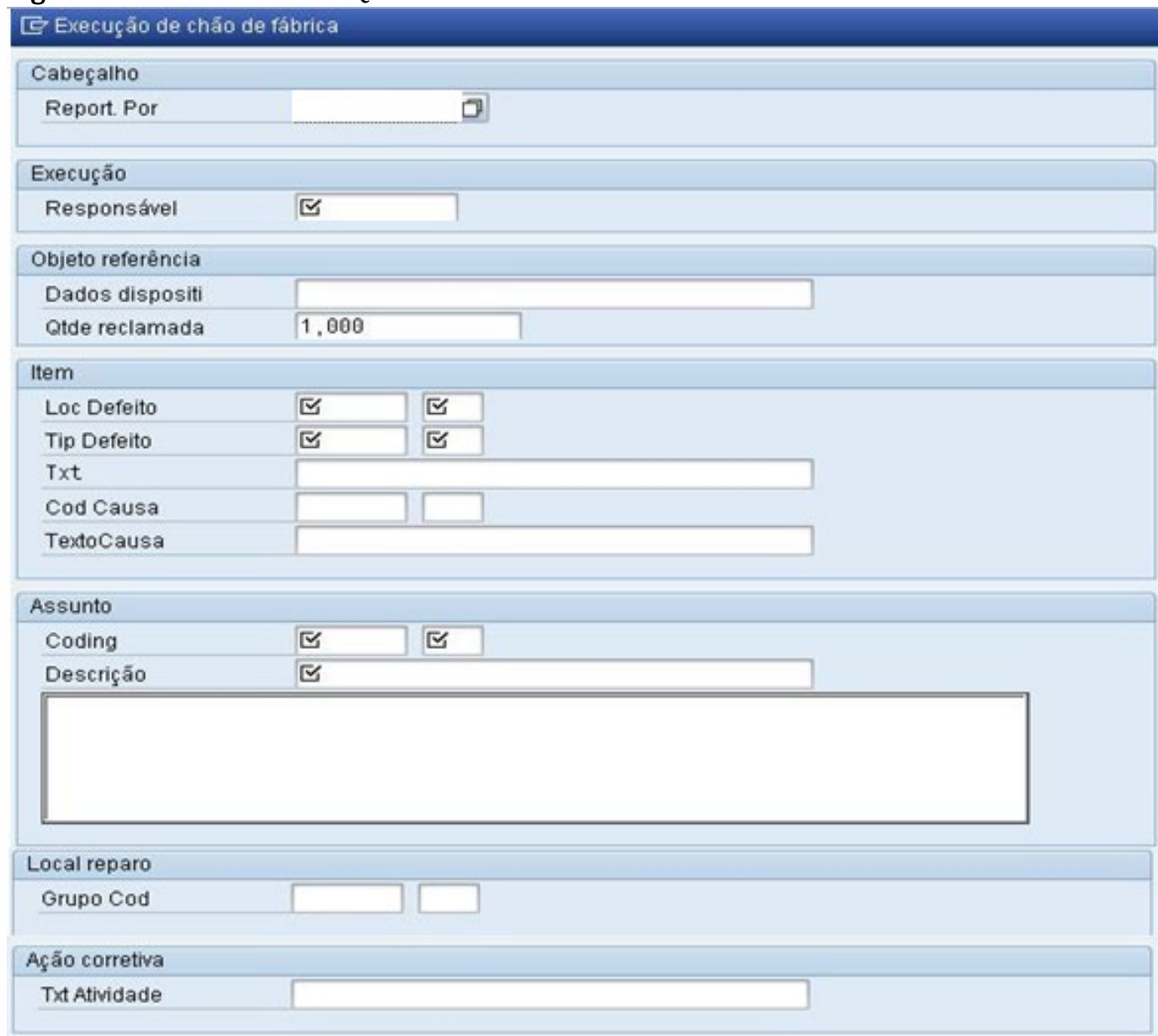

Fonte: Empresa pesquisada.

Conforme a Figura 1, para a abertura de uma Q-note, o controlador, que é o responsável pela abertura e controle da mesma, segue os seguintes passos:

1. Identificar dentro do sistema de gerenciamento o código do item que apresentou problemas no processo produtivo;

2. Identificar a pessoa responsável pela qualidade do produto, que receberá por e-mail a atividade que deverá realizar para resolução da não conformidade aberta;

3. Preencher a quantidade de itens não conformes que foram identificados com falhas;

4. Identificar o local físico que o produto foi localizado, bem como o setor da fábrica; 
5. Título da não conformidade e sua descrição;

6. Material que ocasionou a não conformidade;

7. Identificar ação para a correção do problema;

8. E por fim, criar-se a Q-note.

As Q-notes são utilizadas para registro de problemas simples encontrados nos processos e que podem ser abertos e resolvidos no mesmo dia. Para finalizá-la o controlador verifica o departamento que realizou a não conformidade, confere se sua descrição está correta, corrigindo-a caso seja necessário. Nela deverá estar descrito as atividades realizadas para corrigir a não conformidade, o material que foi substituído e a causa do defeito, o tempo usado (horas) para a correção e o que foi realizado.

O controlador além de gerenciar as Q-notes, reporta em reuniões semanais tudo que foi aberto nas notas para as áreas.

A Q-Note é utilizada como notificação de que as atividades precisam ser realizadas antes que o processo de devolução ao cliente seja finalizado, por isso são utilizadas para documentar não conformidades constatadas nos materiais de produção, tanto internas ou de fornecedores.

\subsubsection{Non-Conformance Corrective Action}

Caso os problemas sejam mais críticos, são abertas as Non-Conformance Corrective Action (NCCA), sendo uma ferramenta que gerencia as não conformidades mais complexas detectadas, tendo como base para abertura as Qnotes.

As NCCAs são utilizadas desta forma, para o caso de não conformidades urgentes e de paradas de linha ou se afetar alguma norma estabelecida pela empresa. Para isso, a empresa conta com equipes multifuncionais, que são formadas por colaboradores das áreas de engenharia, manufatura, qualidade entre outros. Estas equipes analisam de forma mais detalhada estes problemas e a partir das análises realizadas, implantam melhorias no processo.

A estrutura para abertura de uma NCCA é definida por:

- Um originador: É o responsável pela abertura da NCCA e quem define o papel de cada integrante no grupo. Este disponibiliza as informações da não conformidade, identificando as áreas e deliberando os produtos afetados;

- Um gerente: Responsável que tem acessos ao sistema e que possui autonomia de modificar a estrutura da NCCA da forma como achar conveniente. Ele acompanha toda a evolução e faz as cobranças necessárias para que a ação tenha o andamento dentro das datas estabelecidas;

- Um verificador: Este valida todas as ações da equipe, as tarefas realizadas e concluídas passam por ele, que define se as ações estão dentro do especificado e se atendem as solicitações'

- Investigadores: pode ser composto por uma ou mais pessoas que possuem o maior conhecimento sobre a não conformidade, sendo que estes realizarão quase todas as atividades de investigação dos 
problemas, passando por todas as etapas e identificando a causa raiz. $\mathrm{Na}$ primeira etapa, o investigador deve definir a ação de curto prazo, ou ação de contenção, que resolveu ou conteve a não conformidade;

- Membros da equipe multifuncional: A quantidade de membros é definida pelo originador mediante necessidades das atividades de identificação da causa raiz.

Depois de feita a definição dos membros do time pelo originador, a NCCA começa funcionar no sistema, gerando avisos de atividades por e-mail, para cada colaborador envolvido mediante sua especialidade, para que possa colaborar de forma mais rápida e objetiva.

Todos estão integrados na mesma interface e podem visualizar o andamento do processo, cada um possui tarefas distintas que depois de concluídas seguem o fluxo para as demais pessoas. 0 sistema possibilita o anexo de documentos e comprovantes de que a tarefa foi realizada. Depois de concluir esta ação, a tarefa passa pelo verificador que define se a mesma está de acordo e possui as informações necessárias para andamento da NCCA. Caso a atividade não esteja apropriada e a causa raiz não estiver bem definida, o verificador retorna para o investigador juntamente com uma justificativa de qual ação deve ser tomada para validar esta atividade.

Caso o verificador aprovar a ação, a mesma passa para o nível de ação em longo prazo, onde a causa raiz já foi definida durante a ação do investigador e membros da equipe e deve ser projetada neste campo, onde é definido o que deve ser feito para que o problema não se agrave ou se repita.

Após completar todo o ciclo, a ação é concluída pelo verificador, que acompanha todas as fases e aprova todas as ações, cada integrante é informado via e-mail da conclusão da NCCA. 0 gerente acompanha todo o andamento e interfere quando achar necessário, podendo retornar ou aprovar qualquer ação feita pela equipe, tendo autonomia de redefinir ou mudar qualquer membro da equipe.

Finalizada cada etapa e aprovadas pelos responsáveis, a nota é concluída ficando disponível em um histórico do próprio sistema que pode ser consultado através de um número que é originado na sua abertura e permanece até sua conclusão.

\subsubsection{Corrective Action Report}

Caso não houver uma solução do problema dentro do prazo estipulado e a equipe multifuncional não encontrar uma solução viável para o problema, o verificador dispara ações a serem tomadas e envolve as pessoas que achar necessário, através de reuniões diárias onde são definidas as estratégias do processo, utilizando-se de outras ferramentas de gerenciamento internas que envolvem maiores grupos ou outras equipes multifuncionais. Estas ferramentas são denominadas Corrective Action Report (CAR) e seguem o mesmo princípio e funcionalidade da NCCA, mas tem uma abrangência maior, alcançando e envolvendo a mais alta direção da empresa para que as ações necessárias sejam tomadas e a gravidade do problema, seja conhecido e tratado com prioridade máxima, envolvendo esforços de todas as áreas. 
Neste nível, o problema é acompanhado pela supervisão, gerência e direção alcançando proporções maiores dependendo da gravidade. Todas as etapas do processo são acompanhadas e aprovadas por responsáveis que são definidos nestas reuniões, uma é ligada a outra e todos devem concluir suas ações através de prazos estipulados.

O intuito do gerenciador é resolver os problemas dentro da fase de NCCA, pois ao abrir uma CAR, as ações são mais demoradas. Conforme mencionado anteriormente, a CAR tem a mesma funcionalidade que a NCCA. 0 procedimento e as etapas usadas dentro do sistema são o mesmo, a única diferença é o envolvimento de um número maior de pessoas, incluindo a alta gerência e a urgência na sua resolução. Depois de concluída também possui um histórico onde fica armazenada para futuras consultas ou auditorias.

Na Figura 2, pode-se verificar o documento gerado pelo sistema na abertura de uma NCCA ou CAR, bem como os procedimentos mencionados anteriormente, para que a mesma possa dar andamento dentro do sistema e atinja as pessoas necessárias a desenvolver as atividades para sua resolução.

Figura 2: Documento gerado com a abertura de um NCCA ou uma CAR

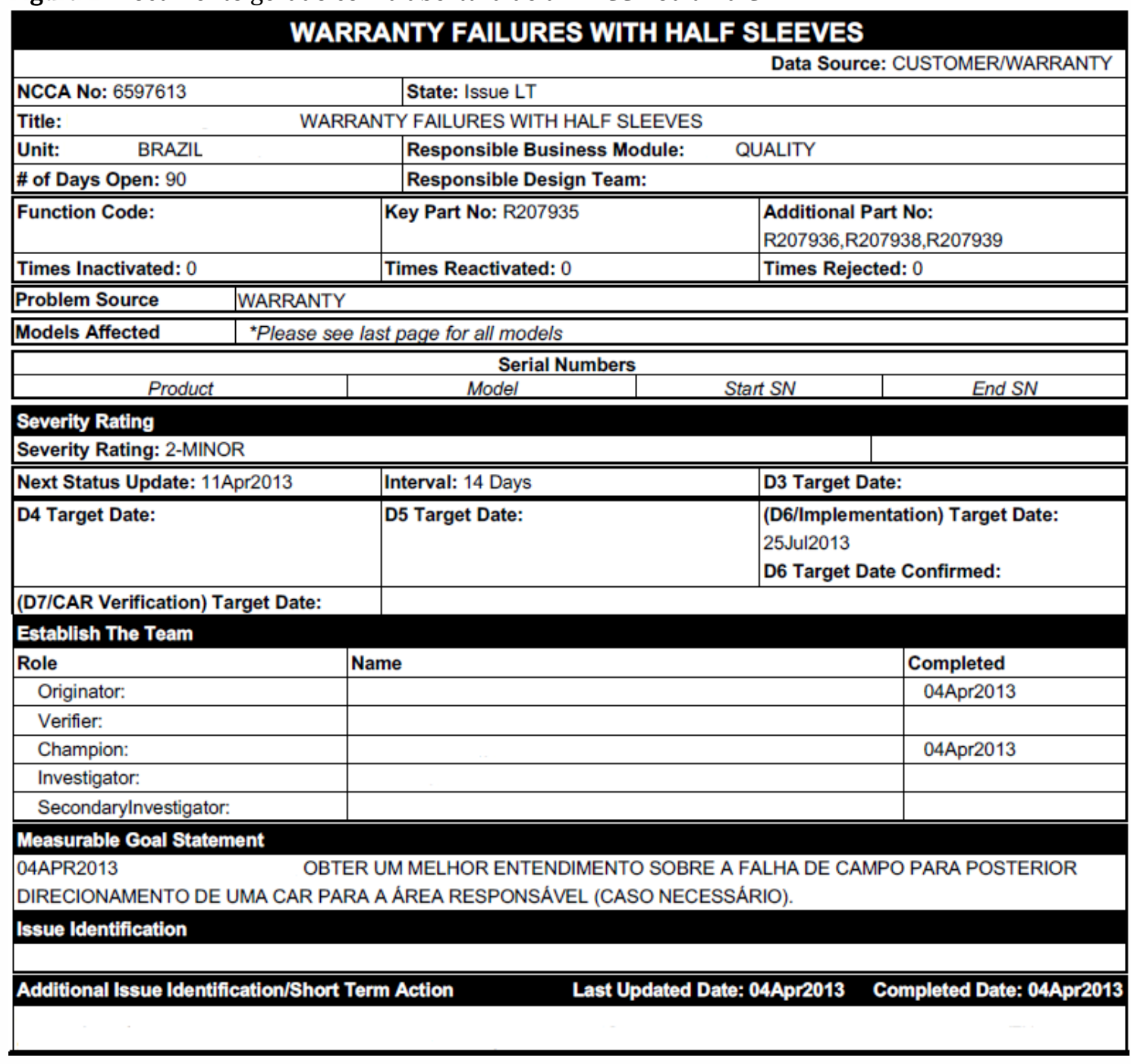

Fonte: Empresa pesquisada. 
As três ferramentas corporativas apresentadas utilizam ferramentas da qualidade para a resolução dos problemas encontrados. As ferramentas da qualidade entram na fase de ações onde o grupo ou o investigador irá usar de seus conhecimentos para prover as informações necessárias. As principais ferramentas utilizadas são: brainstorming, diagrama de Ishikawa, 5 Porquês, 5W1H entre outros, para chegarem à causa raiz dos problemas. 0 sistema segue a metodologia do DMAIC que possui estratégias do 6 Sigma, onde cada letra representa uma etapa do processo: Define (Definir), Measure (Medir), Analyse (Analisar), Improve (Melhorar), Control (Controlar).

As ferramentas corporativas utilizadas e implementadas pela empresa tem uma significativa contribuição para a mesma, pois através delas é possível efetuar diversas atividades com a participação de colaboradores de outras áreas ou de outra unidade da empresa, fazendo com que todas as unidades corporativas estejam interligadas. Desta forma, estimula a todos os envolvidos a cumprirem as datas estipuladas pelo gerente e verificador, pois cada ação tem uma atividade e data a ser cumprida.

0 gerenciamento da qualidade realizado dentro da empresa pesquisada é tão rigoroso que não há dados referentes à abertura de recall. Ou seja, a empresa não teve problemas relacionados aos seus produtos ou lotes, ao ponto de ter de solicitar sua devolução aos clientes a fim de resolvê-lo. Os testes de campo e as análises realizadas são criteriosos para evitar transtornos a imagem da empresa e principalmente a satisfação de seus clientes.

\section{CONCLUSÃO}

Verifica-se que, após a realização de todas as atividades da pesquisa, o objetivo proposto para este estudo de "identificar as práticas do gerenciamento da qualidade em uma indústria multinacional de implementos agrícolas" foi atingido. Além de detalhar as ferramentas corporativas utilizadas e verificar os benefícios que o gerenciamento da qualidade proporciona a empresa e a todos aqueles envolvidos no processo.

Convém ressaltar que no contexto atual, cada vez mais as empresas buscam alternativas para melhorarem a qualidade de seus produtos, garantindo a satisfação dos clientes e principalmente assegurar o sucesso de seu negócio.

0 presente estudo foi realizado em uma empresa multinacional, que desenvolve e aplica técnicas, métodos e ferramentas adaptadas a sua realidade de negócios. Deste modo, em muitos casos não se pode ter muitas informações, ou dados mais aprofundados devido a confidencialidade imposta, trazendo limitações ao estudo.

Através do que foi exposto e apresentado pelo presente trabalho, foi possível verificar como a empresa em estudo trata o gerenciamento da qualidade. Além de usar métodos e ferramentas da qualidade que proporcionam a solução dos problemas, esta agrega as mesmas ferramentas corporativas internas, como a Qnote, NCCA e CAR para a resolução de problemas mais simples e complexos apresentados dentro do processo produtivo, objetivando a resolução dos mesmos o mais rápido possível, envolvendo equipes multifuncionais de diferentes áreas. 
Visa o trabalho em equipe na busca por soluções dos problemas detectados e garantindo que seus processos e produtos atendam ao desejado, ou seja, processos eficazes e entrega de produtos com qualidade e no momento que o cliente desejar. Além disso, destacam-se as ferramentas corporativas disseminação do processo de ação corretiva, onde se constatam a importância de uma análise efetiva das causas das não conformidades para poder eliminá-las, registrando as ações num sistema onde todos podem visualizá-las e acompanhá-las.

A utilização do gerenciamento da qualidade na empresa estudada proporciona muitos benefícios além da qualidade nos processos. Proporcionou excelência no atendimento de problemas de processos, bem como agilidade dos mesmos. Apresentou ganhos de produtividade e um correto direcionamento para todas as ações tomadas durante qualquer problema dentro de um processo. Ainda possibilitou maior conhecimento e integração de todos os envolvidos (stakeholders) e comprometimento em cumprir o que foi programado. Estes benefícios além de garantir uma qualidade contínua nos processos, é o diferencial para que todo projeto venha a ter sucesso, tornando possível a empresa atender aos pedidos dos seus clientes dentro do período solicitado.

Portanto, o aporte da pesquisa está na importância do gerenciamento da qualidade dentro de grandes empresas a nível nacional e internacional. As ferramentas corporativas são rápidas e inovam rapidamente para atender as necessidades dos clientes, visando produzir produtos com qualidade, dando prioridade máxima na resolução de qualquer problema que possa danificar o produto, ou não atender ao pedido no prazo esperado.

Ainda que, este estudo tenha sido desenvolvido através de um estudo de caso em uma empresa de grande porte, acredita-se que, as ferramentas utilizadas pela empresa, devidamente adaptadas, possam servir de referência para outras empresas identificarem as práticas do gerenciamento da qualidade, em consequência melhorar a sua capacitação e maturidade da melhoria contínua, buscando qualidade em todas as etapas do processo, visando produzir produtos que atenda às necessidades dos clientes.

\section{REFERÊNCIAS}

ARAUJO, L. C. G. Gestão de pessoas. São Paulo: Atlas. 2006.

CARPINETTI, L. C. R.; MIGUEL, P. A. C.; GEROLAMO, M. C. Gestão da Qualidade: ISO 9001:2000 princípios e requisitos. São Paulo: Atlas, 2007 p. 1-65.

CHIZZOTTI, A. Pesquisa em ciências humanas e sociais. São Paulo: Cortez. 1995.

COLTRO, A. A gestão da Qualidade Total e suas influências na competitividade empresarial. Cadernos de Pesquisa em Administração, São Paulo, v.1, n. 2. 1996.

COSTA, M. A. M.; SANCHES, C.; MARIETTO, M.L.; SILVA, O. R. Campos e armas da competição: um modelo para formular estratégia de produção nas pequenas e médias empresas. RAI - Revista de Administração e Inovação. ISSN: 1809-2039. 4(3), p 102-116. 2007.

COTA, K. A.; FREITAS, M. A. M. Gestão da qualidade, um desafio permanente: um estudo de caso sobre o processo de manutenção de um sistema de qualidade em uma indústria metalúrgica.

Produto \& Produção, v.14 n.2, p. 59-71, jun. 2013. 
FREITAS, K. D.; QUEIROZ, P. C. F.; MOURA, R. N.; BRITO, A. V.; MELO, V. C. G. C. Aplicação das ferramentas da qualidade em uma panificadora como método de melhoria do processo produtivo: estudo de caso. In Encontro Nacional de Engenharia de Produção, XXXIV, Paraná. Anais... Curitiba: ENEGEP. 2014.

GIL, A. C. Métodos e Técnicas de pesquisa social. 5. ed. São Paulo: Atlas. 1999.

GODOY, L.P.; SCHMIDT, A.S.; NETO, A. C.; CEMFIELD, C. E. R.; SANT’ANNA, L. C. C. Avaliação do grau de contribuição das normas de garantia da qualidade ISO-9000 no desempenho de empresas certificadas. Revista de Administração da UFSM, Santa Maria, v.2, n.1, p. 41-58. 2009.

HARTZ, D., B.; OLIVEIRA, A., K., R. Indicadores do sistema de Gestão da Qualidade como ferramenta de melhoria contínua. In Encontro Nacional de Engenharia de Produção, XXXI, Minas Gerais. Anais... Belo Horizonte: ENEGEP. 2011.

LIMA, J. A; SANTIAGO. P. O. Os primeiros conceitos da gestão da qualidade total. XIV Encontro Regional de Estudantes de Biblioteconomia, Documentação, Ciência da Informação e Gestão da informação. Anais... Maranhão. 2011.

LOBO, N. R.; Gestão da Qualidade. São Paulo: Érica, 2010.

MARSHALL JUNIOR, Isnard et al. Gestão da qualidade. 9. ed. Rio de Janeiro: FGV, 2008.

MATTAR, F. N. Pesquisa de marketing. São Paulo: Atlas. 1999.

MEARS, P. How to stop talking about, and Begin progress toward total quality management. In: Business Horizons. Greenwich, 36, p. 66-68. 1996.

MIGUEL, P. A. C. Qualidade: enfoques e ferramentas. São Paulo: Artliber, 2006.

PLATH, A. M. S.; KACHBA, Y. R.; DIAS, M. C. Gestão da qualidade em empresas de diferentes segmentos do mercado têxtil: um estudo multicaso. In Encontro Nacional de Engenharia de Produção, XXXI, Minas Gerais. Anais... Belo Horizonte: ENEGEP. 2011.

SLACK, N; CLAMBERS, S.; JOHNSTON, R.; BETTS, A. Gerenciamento de Operações e de Processos Princípios e práticas de impacto estratégico. Porto Alegre: Bookman. 2008.

TOLEDO, J. C.; BORÁS, M. Á. A.; MERGULHÃO, R. C.; MENDES, G. H. S. Qualidade: gestão e métodos. Rio de Janeiro: LTC, 2017.

VASCONCELOS, D. S. C.; SOUTO, M. S. M. L; GOMES, M. L. B.; MEQUITA, A. M. A utilização das ferramentas da qualidade como suporte a melhoria do processo de produção: estudo de caso da indústria têxtil. In: Encontro Nacional de Engenharia de Produção, XXIX ENEGEP, Salvador- BA. Anais... Salvador. 2009.

VASCONCELOS, P. H.; ALVES, C. E. L.; SANTOS, S. F. M.; FRANCISCO, A. C. Qualidade de vida no trabalho docente: um estudo de caso em uma instituição de ensino superior. RAI - Revista de Administração e Inovação. ISSN: 1809-2039. 9(2), p 79-97. 2012.

VOSS, C. A. Alternative paradigms for manufacturing strategy. International Journal of Operations and Production Management, Bradford, 15(4), p. 5-16. 1995. 